\title{
HAS THE TRADITIONAL SOCIAL PERCEPTION ON NURSES CHANGED? ATTRIBUTION OF STEREOTYPES AND GENDER ROLES
}

\author{
¿HA CAMBIADO LA \\ PERCEPCIÓN SOBRE LOS Y LAS \\ ENFERMERAS? ATRIBUCIÓN DE \\ ESTEREOTIPOS Y ROLES DE \\ GÉNERO
}

\author{
MARÍA ARANDA ${ }^{1}$, MARÍA DEL RoSARIO CASTILLO-MAYÉN ${ }^{1}$ Y \\ BEATRIZ MONTES-BERGES ${ }^{1}$
}

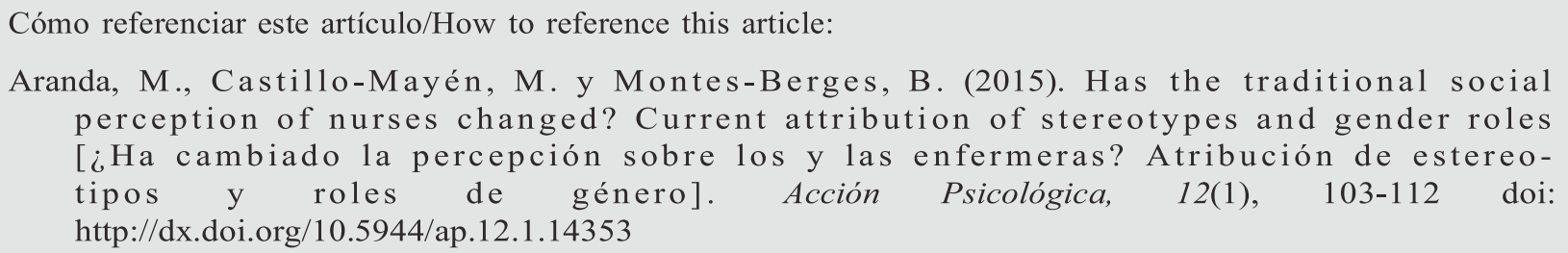

\begin{abstract}
Nursing has traditionally been regarded as a female profession. However, in recent years there has been an increase of men. Despite this change, patriarchy still has a profound influence on how general population, patients and even nursing students perceive this occupation. Taking this background into account, the present research aims to analyze gender stereotype and gender role assignment to male and female nurses. A quasi-experimental study was conducted on 121 participants from three groups: patients, non-patients
\end{abstract}

and nursing students. Gender stereotypes and gender roles assignment were analyzing using two factors: level of social domination orientation, and the group membership. Results showed that the gender stereotypes assignment to male and female nurses displayed some similarities; therefore a less stereotypical perception was observed comparing with other recent research. Moreover, participants low in social dominance orientation indicated a preference to traditional gender roles. Considering the group we found a traditional assignment of gender stereotypes over female and male nurses, even among nursing students. In sum, despite the dynamism of the nurses' social perception, still remains a gender bias that needs to be avoided.

Correspondencia: María Aranda. Universidad de Jaén.

Email: aranda@ujaen.es

${ }^{1}$ Universidad de Jaén.

Recibido: 08 de abril de 2015

Aceptado: 02 de mayo de 2015 
Keywords: gender roles; gender stereotypes; nursing; social dominance orientation.

\section{Resumen}

La enfermería es considerada tradicionalmente como una profesión femenina, aunque en los últimos años se aumentado el número de hombres. A pesar de este incremento, las estructuras patriarcales siguen influyendo en la percepción que la población, los pacientes e incluso los estudiantes de enfermería tienen sobre esta ocupación. Partiendo de esta realidad, la presente investigación tiene como objetivo analizar la asignación de estereotipos y roles de género a enfermeras y enfermeros. El estudio, con un diseño cuasi-experimental, se realizó con 121 participantes procedentes de tres grupos: pacientes, no pacientes y estudiantes de enfermería. Tanto la atribución de estereotipos como de roles de género se analizó atendiendo a dos factores: la orientación dominación social y la pertenencia a los grupos mencionados. Los resultados mostraron que la distribución de estereotipos de género a enfermeras y enfermeros presentó similitudes, por lo tanto, obtuvimos una percepción menos estereotipada que investigaciones recientes. Además, los participantes con baja orientación a la dominancia social eligieron roles de género tradicionales. Teniendo en cuenta el grupo de pertenencia encontramos que la asignación tradicional de estereotipos de género influyó en la imagen de los y las enfermeras, incluso entre los estudiantes de enfermería. Se puede concluir que a pesar del dinamismo mostrado en la percepción de los y las enfermeras, sigue existiendo un sesgo de género sobre el que habría que seguir trabajando.

Palabras clave: roles de género; estereotipos de género; enfermería; orientación a la dominancia social.

\section{Introduction}

Nursing in Spain has always been conditioned by a strong influence of the gender role division (MosquedaDíaz, Paravic-Klijn, \& Valenzuela-Suazo, 2013). In addition, this profession was performed exclusively by women and was considered an extension of their caregiver role (Stanley, 2012). Both circumstances make nursing a feminized profession. This partnership (nurs- ing and femininity) was found to be closely related in a cross-cultural study going back almost 30 years (Austin, Champion, \& Tzeng, 1985), and this seems to be true today. In fact, different researchers have found that, nowadays, social perceptions of nursing in Spain remain anchored to this traditional image (e.g., Bernalte-Martí, 2015; Calvo-Calvo, 2014; Errasti-Ibarrondo, Arantzamendi-Solabarrieta, \& Canga-Armayor, 2012). Nursing is considered by many as a female career, and describe this profession using words such as "caring for others", "vocation", "altruism", "kindness", "sensitivity" and "serving others" (Rodríguez-Ramírez \& Escalona-Aguilar, 2007). The traits associated with nurses can be explained by the differential attribution model of gender stereotypes proposed by Bakan (1966) or the stereotype content theory established by Fiske (2002). This tendency to distinguish between feminine and masculine roles and characteristics is a very common psychosocial process. This distinction has a strong hierarchical component that concedes greater status to masculine traits (Rudman, MossRacusin, Nauts, \& Phelan, 2012). In according with the Bakan's theory, the above mentioned attributes are strongly associated with communality (the dimension related to showing concern and consideration towards others). This concept constitutes a rigid model regarding women, and it extends the traditional role of the caregiver, which in turn would keep women away from traditional male-dominant fields.

Other authors also posit that people organize groups into categories based on gender stereotypes (Cuddy, Glick, \& Beninger, 2011; Fiske, 2015): (a) competence, defined as the ability to achieve professional and prestigious goals (related to agentic characteristics); and (b) sociability, based on sympathy and interpersonal skills, and linked to communal traits. Given that perceptions of agency and communality are associated with high and low status roles respectively, the image of nursing as a feminized profession has come with some negative connotations. In any case, both theories, distinguishes between a dimension more feminized, oriented to people (communality or sociability/warth) and a dimension more masculinized, oriented to the tastk (agency or competence).

The relationship between nursing and women is so strong that there are even professionals in this sector who identify medicine with male stereotypes and nursing with female ones (Benalte-Martí, 2015). This association implies a less positive consideration of nursing compared to some masculinized occupations, such as medicine. In this regard, studies have shown that feminized professions have less power (López-Zafra, García-Retamero, Diekman, \& Eagly, 2008), are more invisible, and have not been positive valued in economic terms (e.g., Arroyo, Lancharo, Romero, \& Morillo, 2011). This perception, 
based on a traditional and patriarchal culture, has had an impact not only on patients but also on the self-concept and self-esteem of nurses themselves. This stereotypical image even affects one's decision to pursue nursing studies, particularly men (Dante, Rizzi, Ianderca, \& Palese, 2013). This finding is similar to that reported in a recent study carried out in Italy, where information available regarding the nursing profession was found to be incorrect, with this situation influencing their decision to study a nursing degree (Dante et al., 2013).

Despite all the background above, social changes related to gender equality opportunities that have taken place in recent decades could affect perceptions of nursing. Generally speaking, in western society, and specifically in Spain, more men are pursuing nursing studies and subsequently enter this profession (ErrastiIbarrondo et al., 2012). Therefore, according to Social Role Theory, this change in social roles could produce a change in gender stereotypes (view Eagly, 1987). These changes have been reported in many studies (e.g., Dasgupta \& Asgari, 2004; Lenton, Bruder, \& Sedikides, 2009).

In sum, we have a new framework for an old profession. Thus, the question we raise is whether people still use traditional stereotypes to describe nurses, both men and women. To provide an answer to this issue, we analyze the perception of different social agents. This information is crucial in order to obtain a complete and objective picture of nursing, given that its image bears subtle differences depending on the person's experience in a medical context. Moreover, in the present study another variable that may explain the assignment of gender stereotypes is included: the social dominance orientation (SDO).

SDO was proposed by Social Dominance Theory (SDT; Pratto, Sidanius, Stallworth, \& Malle, 1994). The theory is based on the assumption that all human societies tend to be structured as hierarchical systems in which one group is established as hegemonic. The dominant group is characterized by having a disproportionately large share of positive social value (e.g., political power, social status, access to resources). Accepting the myths and ideologies that justify this hierarchical system ensures its maintenance. These include stereotypes and other sets of beliefs such as racism, sexism and ethnocentrism, to name a few. In this context, SDO is defined as the desire to maintain intergroup hierarchy and unequal relations, even if this implies ingroup domination or outgroup subordination (Ho et al., 2012). Therefore, the higher the SDO scores, the greater the acceptance of hierarchy-enhancing myths and ideologies. As for the relationship between SDO and stereo- types, Tausch and Hewstone (2010) found that the desire to maintain social hierarchies is negatively related to greater stereotype change.

In the present study, we analyzed three groups' perception of female and male nurses, each one with different experiences in the medical context: patients, nonpatients and nursing students. Specifically, we proposed two goals. The first one was to analyze stereotype assignment to female and male nurses based on two factors: one's experience in the medical context (patients, nonpatients and nursing students) and SDO levels (high SDO vs. low SDO). The second goal was to examine the roles attached to female and male nurses taking into account the two aforementioned factors. To achieve this second aim, we created three gender role-based scenarios in which participants could choose between a female or male nurse (see Material section).

Regarding our first aim, two hypotheses were proposed. First, we anticipated that both female and male nurses would be described using feminine stereotypes more than masculine ones. However, participants from the patient and nursing student group would assign some masculine stereotypes to nurses in comparison with nonpatient group (hypothesis 1). This prediction is based on Bakan's theory (1966). Taking into account the recent rise in male nursing students, the stereotypes and roles associated with this profession may have changed, mainly among those participants that have direct contact with nurses. Second, we expected that, given the relationship between SDO and stereotype maintenance, participants with high SDO levels would describe female and male nurses more stereotypically than individuals presenting low SDO levels (hypothesis 2).

With regard to the second aim concerning gender role assignment to nurses, two hypotheses were considered. First, we expected to observe competence and leadership roles (agentic dimensions) more with male nurses than with their female counterparts, whereas social skills (communal dimension) would be more applicable to female nurses. The reason to include the leadership as a second agentic dimension is related to the stereotypicality studies; according with them the term leader "stereotypicality" is used to refer to the degree to which the leader is perceived as having the characteristics considered desirable in a good leader (Hogg, Hains, \& Mason, 1998; Montes-Berges \& Moya, 2009). On the one hand, and taking into account that nursing is so feminized profession, is not strange thinking that a good nurse leader could be a person with social skills. On the other hand, leadership has been considered as a trait of the agentic dimension. In order to check this, leadership was included as an independent dimension. This role-congruent attribution based 
on nurses' gender is likely to be more relevant in the non-patient group where a more stereotypical image would be seen (hypothesis 3). Second, we anticipated that participants who presented high SDO levels would choose a female nurse in the social skills scenario, whereas a preference for male nurses would be recorded in relation to competence and leadership (hypothesis 4).

\section{Method}

\section{Participants}

The final sample consisted of 121 subjects, 33 men and 88 women, aged 18 to 66 years $(\mathrm{M}=22.86$ years, $\mathrm{SD}=14.17$ ). Intentional-cluster sampling to select and assign participants to three groups were used. The groups were the following: patients $(n=40$, age average $25.4, \mathrm{SD}=16.8)$, non-patients $(\mathrm{n}=41$, age average 24.3, $\mathrm{SD}=15.5)$ and nursing students $(\mathrm{n}=40$, age average $22.7, \mathrm{SD}=12.8$ ). Specific criteria were assumed to be included in each group: (a) patients must have visited the doctor or hospital at least once a month during the past year and all of them were hospitalized the same day they came to be made medical proofs; (b) non-patients must not have visited the doctor or hospital more than twice during this period; (c) nursing students were close to completing their first year of Nursing Degree. The educational level was carefully balanced between the three groups. All participants were from Jaén (Spain).

\section{Materials}

Social Dominance Orientation Scale (Pratto et al., 1994). We used the adapted and validated Spanish version of this test by Montes-Berges and Silván-Ferrero (2003), which assesses a tendency towards social dominance (e.g., "The value that have some groups of persons is larger than the other"). It consists of 16 items, each scored on a 7-point Likert scale $(1=$ strongly disagree, $7=$ strongly agree). Eight items $(2,5,7-10,13$, 15) are reverse scored. High scores indicate a greater tendency towards social dominance, whereas low scores point to the opposite. The Cronbach's Alpha value in our study was .89 .

Current Gender Stereotypes Scale (Castillo-Mayén $\&$ Montes-Berges, 2007). This scale comprises a list of 242 adjectives related to gender stereotypes. Participants completed two versions of this scale, one used to describe male nurses and another one to describe female nurses. They were asked to rate each adjective on a 7- point scale, where "1" indicated that the adjective was "not at all characteristic of the person", and "7" was "completely characteristic". The survey included four groups of stereotypes: positive feminine stereotypes (PFS; such as "warm" and "people-oriented"), negative feminine stereotypes (NFS; such as "dependent" and "fearful"), positive masculine stereotypes (PMS; such as "self-efficacious" and "competent"), and negative masculine stereotypes (NMS; such as "selfish" and "inexpressive").

Role assignment task: competence, social skills and leadership (specifically created to develop the study). In the task, three specific scenarios in the hospital context were presented. The first two involved descriptions of patients with different needs, whereas the third relates to moving up the hierarchical ladder. Participants had to choose between a female or male nurse (Mary or Albert) depending on the situation. We based this on the agentic and communal traits associated with gender roles (Bakan, 1966). Specifically, we devised the cases:

Competence (Agentic Dimension): "A relative has been involved in a car crash. They are young, strong and energetic. The accident has left the patient seriously injured but they've got a chance of making a recovery if they urgently receive the best care possible, where swift and efficient decisions have to be made. Who would you choose?"

Social skills (Communal Dimension): "A relative of yours has been suffering from a malignant tumor for the last year and a half. There's no cure and he or she is simply waiting to die. They are extremely anxious and you want them to be looked after by a nurse who can help them feel at ease and die peacefully. Who would you choose?"

Leadership (Agentic Dimension): "The chief of service has just retired and you are asked to promote someone from the team you lead. You have a choice of two candidates, Mary and Albert, both of whom have dedicated more than 5 years to the department and have gone above and beyond in their nursing duties. Who would you choose?"

\section{Procedure}

All participants were administered the questionnaire composed by the scales and the role assignment task (with its three cases). Specifically, nursing students were asked to participate after class. In the instructions they were asked to respond from the perspective of nursing students. Patients group consisted of people who were 
hospitalized during the data collection. Therefore, they have passed diagnostic tests once derived from the family doctor to specialist. The data collection was carried out in a hospital room set up for the occasion. Finally, non-patients group where selected from college students, and the questionnaire was administered in a classroom at the university campus. Before answering it, participants were informed about the voluntary and anonymous nature of the study. Ethical approval was obtained from the Ethics Committee of the University of Jaén prior to data collection. Participants were also given brief instructions on how to fill in the self-report measures and the task. Participants took around 20-35 minutes to complete. Following D'Amato's algorithm, the questionnaire, scales and the role assignment task were counterbalanced in order to avoid possible order effects.

In relation to the design, a quasi-experimental study was carried out. The measures were taken once in time. Thus, there was not experimental mortality. The data collected were exploited using a software package for statistical analysis (SPSS v.19). In order to provide information about our two aims (stereotype assignment to male and female nurses, and distribution of roles depending on nurse' gender) the following analysis were conducted: analysis of variance (ANOVA), multivariate analysis of variance (MANOVA), a comparison of means. In all cases, the confidence interval was set at $5 \%$.

\section{Results}

First of all, analyses to check the possible counterbalance effects were carried out. No counterbalance effects were found, all F's $\leq .1 .263, p \geq .292$.

The first hypothesis anticipated the assignment of stereotypes depending on the membership of one the three groups (patients, non-patients and nursing students). A MANOVA was performed to determine such group differences. The results showed that, controlling the effect of some variables such as the study level and age, significant differences were found among groups in assigning positive stereotypes to female nurses, both feminine, $\mathrm{F}(2,120)$ $=3.52, p=.03, \mathrm{y} 2=.46$, and masculine, $\mathrm{F}(2,120)=3.12$, $p=.04, \mathrm{y} 2=.13$. Non-patients assigned more PFS to female nurses compared with the other two groups conducting a comparison of means using Tukey's HSD test (Standard error's $=.13, p$ 's $\leq 0.4$, Mnon-patients $=5.32 \mathrm{vs}$. Mstudents $=5.01$ vs. Mpatients $=4.80)$. Regarding the perceptions of male nurses, differences were observed among groups for NFS, $\mathrm{F}(2,118)=3.20, p=.04, \mathrm{y} 2=.09$. Nursing students described male nurses using more NFS than patients and non-patients (Standard error's $=.16, \mathrm{p}$ 's $\leq$ 0.4 , Mstudents $=3.28$ vs. Mnon-patients $=2.90$ vs. Mpatients $=2.77$ ).

To examine stereotypes assignment to nurses in each group, we performed a comparison of means for related samples. The analysis showed that patients used more PFS to describe female nurses than male nurses, $\mathrm{t}(39)=3.24, p$ $=.002, \mathrm{y} 2=.07$. They also assigned more NFS to female nurses than to their male counterparts, $\mathrm{t}(39)=3.11, p=$ $.003, \mathrm{y} 2=.14$.. Non-patients assigned all categories of stereotypes congruently with gender. This group described female nurses using more PFS, $\mathrm{t}(40)=6.80, p=.001, \mathrm{y} 2=$ .10 , and more NFS, $\mathrm{t}(40)=6.80, p=.015, \mathrm{y} 2=.29$ than male nurses. As for masculine stereotypes, the non-patient group assigned more PMS, $\mathrm{t}(40)=2.47, p=.018, \mathrm{\eta} 2=$ .12 , and more NMS, $\mathrm{t}(40)=-2.81, p=.008, \mathrm{y} 2=.18$ to male nurses than to their female counterparts (see Table 1). Finally, nursing students assigned more PFS, t(37) = $5.86, p=.001, \mathrm{j} 2=.21$, and more PMS, $\mathrm{t}(37)=4.92, p=$ $.001, \mathrm{y} 2=.20$ to female nurses than to their male peers. This group used more NMS to describe male nurses as opposed to female nurses, $\mathrm{t}(37)=-3.84, p=.001, \mathrm{y} 2=.19$ (Table 1).

Table 1

Differences on gender stereotypes' assignment to male and female nurses regarding the belonging group.

\begin{tabular}{|c|c|c|c|c|c|c|}
\hline & & \multicolumn{2}{|c|}{$\begin{array}{l}\text { Stereotypes assigned to fe- } \\
\text { male nurses }\end{array}$} & \multicolumn{2}{|c|}{$\begin{array}{c}\text { Stereotypes assigned to male } \\
\text { nurses }\end{array}$} & \multirow[t]{2}{*}{$p$} \\
\hline & & $\mathrm{M}$ & $S D$ & $M$ & $S D$ & \\
\hline \multirow{4}{*}{ Patients } & Femenine + & 4.80 & 0.58 & 4.53 & 0.68 & .002 \\
\hline & Femenine - & 3.04 & 0.71 & 2.77 & 0.85 & .003 \\
\hline & Masculine + & 4.57 & 0.72 & 4.86 & 0.63 & .662 \\
\hline & Masculine - & 2,76 & 0.58 & 2.98 & 0.94 & .094 \\
\hline \multirow{4}{*}{ Non- Patients } & Feminine + & 5.32 & 0.58 & 4.63 & 0.48 & .001 \\
\hline & Feminine - & 3.19 & 0.88 & 2.90 & 0.74 & .015 \\
\hline & Masculine + & 4.90 & 0.62 & 5.07 & 0.55 & .018 \\
\hline & Masculine - & 2.74 & 0.65 & 3.03 & 1.01 & .008 \\
\hline \multirow{4}{*}{$\begin{array}{l}\text { Nursing } \\
\text { Students }\end{array}$} & Feminine + & 5.01 & 0.59 & 4.60 & 0.48 & .001 \\
\hline & Feminine - & 3.25 & 0.60 & 3.28 & 0.53 & .481 \\
\hline & Masculine + & 4.88 & 0.48 & 4.76 & 0.65 & .001 \\
\hline & Masculine - & 2.90 & 0.62 & 3.28 & 0.71 & .001 \\
\hline
\end{tabular}


Table 2

Differences on gender stereotypes' assignment depending on the participant's SDO level.

\begin{tabular}{|c|c|c|c|c|c|c|}
\hline & & \multicolumn{2}{|c|}{$\begin{array}{c}\text { Stereotypes assigned to } \\
\text { female nurses }\end{array}$} & \multicolumn{2}{|c|}{$\begin{array}{c}\text { Stereotypes assigned to } \\
\text { male nurses }\end{array}$} & \multirow[t]{2}{*}{$\mathrm{p}$} \\
\hline & & $M$ & $S D$ & $M$ & $S D$ & \\
\hline & Feminine + & 4.79 & 0.79 & 4.42 & 0.51 & .001 \\
\hline $\begin{array}{l}\text { High-SDO } \\
(\mathrm{n}=32)\end{array}$ & $\begin{array}{l}\text { Feminine - } \\
\text { Masculine + } \\
\text { Masculine - } \\
\text { Feminine + }\end{array}$ & $\begin{array}{l}3.18 \\
4.64 \\
2.79 \\
5.04\end{array}$ & $\begin{array}{l}0.86 \\
0.65 \\
0.65 \\
0.44\end{array}$ & $\begin{array}{l}2.98 \\
4.42 \\
3.08 \\
4.60\end{array}$ & $\begin{array}{l}0.91 \\
0.51 \\
0.95 \\
0.49\end{array}$ & $\begin{array}{l}.003 \\
.030 \\
.014 \\
.001\end{array}$ \\
\hline $\begin{array}{l}\text { Low-SDO } \\
(n=24)\end{array}$ & $\begin{array}{l}\text { Feminine - } \\
\text { Masculine + } \\
\text { Masculine - }\end{array}$ & $\begin{array}{l}3.13 \\
4.75 \\
2.80\end{array}$ & $\begin{array}{l}0.64 \\
0.47 \\
0.55\end{array}$ & $\begin{array}{l}2.80 \\
4.60 \\
2.99\end{array}$ & $\begin{array}{l}0.69 \\
0.49 \\
0.78\end{array}$ & $\begin{array}{l}.022 \\
.064 \\
.173\end{array}$ \\
\hline
\end{tabular}

With regard to the second hypothesis (impact of SDO levels on stereotype assignment), a comparison of means for related samples was conducted. Two groups were formed according to the percentiles 25 and 75 ; hence, participants whose SDO scores were lower than the 25th percentile were assigned to the low SDO group $(\mathrm{n}=24)$, and participants whose SDO scores were higher than the 75th percentile were assigned to the high SDO group $(n=32)$. The results showed that high-SDO participants assigned more positive stereotypes, $\mathrm{t}(29)=3.53, p=.001, \mathrm{y} 2=.12$, more negative feminine ones, $\mathrm{t}(29)=3.19, p=.003, \mathrm{y} 2=.22$ and more PMS to female nurses than to their male counterparts, $\mathrm{t}(29)=2.27, \mathrm{p}=.030, \mathrm{y} 2=.24$. They also assigned more NMS to male nurses than to female nurses, $\mathrm{t}(29)=-2.61, p=.014, \mathrm{y} 2=.19$. The only differences in the assignment of feminine stereotypes seemed to relate to low-SDO participants, where female nurses received more positive and more negative feminine stereotypes than male nurses, $\mathrm{t}(26)=4.68, \mathrm{p}=.001, \mathrm{p} 2=$ .28 , and $\mathrm{t}(26)=2.44, p=.022, \mathrm{y} 2=.08$, respectively (Table 2).

To confirm the third hypothesis about the performance of the three groups in the role distribution task a MANOVA was used, including study level and age as covariables. Once controlled the effect of the two unknown variables, non-significant differences were observed between the scores for each group in the competence and social skills scenarios, $\mathrm{F}(2,113)=.818, p=$
$.44, \mathrm{y} 2=.03$, and $\mathrm{F}(2,113)=2.71, p=.070, \mathrm{y} 2=.01$, respectively. However, there were significant differences in the leadership situation, $\mathrm{F}(2,113)=25.93 ; p=.001, \mathrm{y} 2$ $=.10$. Specifically, significant differences were found between the three groups. When examining the three means, it was shown that the patients group chose to promote the male nurse over the female nurse more often, whereas both non-patients and nursing students chose the female nurse more frequently. These impressions were supported by the corresponding comparison of means using Tukey's HSD test (Table 3).

Finally, an ANOVA was conducted to determine differences in the discrimination task depending on the participant's SDO level (hypothesis 4). No differences were found between high-SDO and low-SDO participants for either competence, Mhigh-SDO $=1.37$ vs. Mlow-SDO = 1.58 , or leadership, Mhigh-SDO $=1.41$ vs. Mlow-SDO = 1.28. Differences were only observed in social skills, where low-SDO participants chose the male nurse more often for the social skill task than high-SDO participants, $\mathrm{F}(1,117)=4.18, p=.048$, Mhigh-SDO $=1.06$ vs. Mlow$\mathrm{SDO}=1.25$.

\section{Discussion}

In the present study, we have examined social perceptions of nursing professionals, identifying whether the

Table 3

Tukey's HSD test between the three samples on leadership selection task.

\begin{tabular}{llrr}
\hline (I) Samples & (J) Samples & Mean Differences (I-J) & $\boldsymbol{P}$ \\
\hline \multirow{2}{*}{ Nursing Students } & Non Patients & -.15 & .205 \\
& Patients & -.73 & .001 \\
\multirow{2}{*}{ Non Patients } & Nursing Students & .15 & .205 \\
& Patients & -.58 & .001 \\
Patients & Nursing Students & .73 & .001 \\
& Non Patients & .58 & .001 \\
\hline
\end{tabular}


image is the same across different groups depending on their experiences in a medical context (patients, nonpatients and nursing students) and their SDO levels.

Regarding our first hypothesis about differences in assigning stereotypes to male and female nurses, the results showed that there were only differences between the three groups concerning feminine stereotypes. Specifically, and as anticipated in hypothesis 1 , the nonpatient group demonstrated greater stereotypical assignment, using more gender-congruent traits for male and female nurses. Especially, this group was the one that considered that female nurses have more positive feminine stereotypes. Meanwhile, the patient group perceived male and female nurses differently but only in relation to feminine stereotypes. They associated more feminine attributes to female nurses than to their male counterparts. Also, as we predicted, nursing students offered a non-stereotypical image of nurses. This group described female nurses using more positive feminine and masculine stereotypes, whereas they described male nurses using more negative masculine and feminine stereotypes.

This first set of results can be explained by the general public having less knowledge about the differential traits between male and female nurses given their lack of experience, which calls for more stereotypes to be used in order to describe them. Not surprisingly, a primary function of stereotypes is to provide information fast in case the observer has no experience with the stimulus (Pratkanis, Breckler, \& Greenwald, 2014). Regarding nursing students, because there is still a considerable gap between the number of men and women pursuing this career, the opinions of the future female nurses have more influence on the results. Moreover, given that they see themselves as joining this group of professionals shortly, they describe nurses using positive adjectives. Thus, Social Identity Theory (Tajfel \& Turner, 1986) calls this behaviour in-group favouritism. Finally, patients described female nurses using more masculine stereotypes because they see them as working independently and competently (agentic dimension). This group also described male nurses using less masculine stereotypes due to nursing's traditionally feminine role. This finding supports the proposals made by Smith and Zárate (1992) in their Prototype Model, where changes in stereotypes about a given group are possible via contact with a counter-stereotypical prototype.

In terms of our second hypothesis, we expected participants with high SDO levels to describe female and male nurses more stereotypically than those with low SDO levels. Indeed, the results showed a strong relationship between SDO levels and stereotype assignment. Specifically, high-SDO participants assigned more positive and negative feminine stereotypes and more positive masculine stereotypes to female nurses than to their male counterparts. Moreover, they assigned more negative masculine stereotypes to male nurses than to female nurses. In contrast, low-SDO individuals only recorded differences in positive and negative feminine stereotype assignment, where female nurses were described using more positive and negative feminine stereotypes than male nurses, bringing their opinions more in line with the stereotype. These results might be suggesting that high-SDO participants are in support of women who adapt to their gender stereotypes and roles, practicing a traditionally female-dominant profession. For this reason, high-SDO participants assigned female nurses attributes associated with being good workers, which coincides with positive masculine stereotypes (e.g. competent, powerful, self-efficient). In contrast, they find themselves punishing male nurses because their job does not come under traditional male roles, depriving them the privilege of receiving these traits.

For our third hypothesis, we predicted that competence and leadership roles would correspond more to male nurses than to female nurses, whereas social skills would be viewed as more female-oriented. This congruent role attribution based on nurses' gender would be more relevant in the non-patient group, which would offer the most stereotypical image. Specifically, we found that all three groups equally chose male and female nurses when the task required some type of social skill or competence. Bearing in mind that social skills are strongly related to women, this result could be an indication that masculine stereotypes are changing due to changes in men's social roles (Eagly, 1987). As for competence, there were no differences in terms of preferences for a male or female nurse across the sample groups. This perception of "efficacy" is not completely supported by conclusions from some previous studies where, for example, greater confidence was placed in the effectiveness of male nurses over their female peers, highlighting their independence and technical expertise (Celma \& Acuña, 2009). Finally, in the leadership scenario, nursing students and non-patients opted more for the female nurse as chief of service, whereas patients showed preference for the male nurse. A possible explanation could be that a patient's state of health is likely to prompt a more stereotypical response as they try to reduce their stress levels. Patients would display stress because of their illness and ignorance about their diagnosis (Cohen \& Lazarus, 1979). To avoid heightened anxiety, they preferred to base their decisions on social consensus (Tajfel \& Turner, 1986). Taking into account the perceived consensus on stereotypes, by using them patients would thus avoid feelings of anxiety that come from stating personal opinions. 
The last hypothesis considered the role played by SDO in the role distribution task. We anticipated that high-SDO participants would choose a female nurse more often in the social skills situation, whereas they would favor a male nurse when it comes to competence and leadership. No differences were found in the task based on participants' SDO levels for either competence or leadership. However, the social skills scenario yielded an interesting result. Low-SDO participants generally chose a female nurse over a male nurse compared with high-SDO individuals. It seems somewhat contradictory that precisely low-SDO participants should choose a female nurse in this particular situation. This result may seem illogical considering how low-SDO people promote egalitarian values, especially when some studies have found that high-SDO individuals tend to describe the low status group, in this case women, as more incompetent yet warm (Oldmeadow \& Fiske, 2007). In our study it appears that low-SDO people, wanting to come across as equal rather than counter-stereotypical, would chose a female nurse in this situation because a women's suitability to this role does nothing to harm this gender group.

The results of this study have provided relevant insight into society's image of nurses. We have observed a less stereotypical perception of female and male nurses compared with other research (e.g., Bernalte-Martí, 2014; Calvo-Calvo, 2014; Errasti-Ibarrondo et al., 2012). This finding is consistent with some psychosocial theories that address the maintenance and evolution of social stereotypes (e.g., Eagly, 1987). In general, gender stereotypes are changing at the same time that men's and women's roles are changing. The incorporation of women into the world of work, and men into some traditionally female-dominant occupations, has inevitably led to gender-role adaptation. However, the evolution of gender stereotypes in nursing reflects a specific tendency: female nurses are perceived as having both feminine and masculine traits (although the first type slightly outweighs the second), whereas male nurses are also described in ways that are traditionally related to communality. Moreover, the data gathered in this research confirm that it is possible to overturn the stereotypical image of nurses through mere exposure to the exemplar being stereotyped (as in the case of the patient group). This process has been raised as a successful strategy to change attitudes: the repeated exposure to a stimulus could improve people's attitudes towards it (Bohner \& Wänke, 2014).

Despite the valuable contribution made by this study, it is not without its limitations. First, due to the disproportionate number of female students, their influence over the results is greater. Second, the very size of the
EGA scale may have caused the participants to experience excessive tiredness. Finally, the study sample could be larger and extended to other cities in order to generalize the results.

In the future, we hope to further this work by analyzing the changing patterns of stereotypes related to other professions (e.g., doctors) in a cross-cultural study, where we will examine to what extent these stereotypes evolve and promote changes in these social roles.

\section{References}

Arroyo, A., Lancharo, I., Romero, R., \& Morillo, M. (2011). La enfermería como rol de género [Nursing has gender role]. Index de Enfermería, 20(4), 248-51.doi:org/10.4321/S113212962011000300008

Austin, J. K., Champion, V. L., \& Tzeng, O. C. S. (1985). Crosscultural comparison on nursing image. International Journal of Nursing Studies, 22(3), 231-239. doi:10.1016/0020-7489(85)900069

Bakan, D. (1966). The duality of human existence: Isolation and communion in Western man. Rand McNally, Chicago.

Bernalte-Martí, V. (2015). Minoría de hombres en la profesión de enfermería. Reflexiones sobre su historia, imagen y evolución en España [Minority of men in nursing profession. Reflections on its history, image and evolution in Spain]. Enfermería Global, 14(1), 328-334.

Bohner, G., \& Wänke, M. (2014). Attitudes and attitudes change. New York (NY): Psychology Press.

Calvo-Calvo, M. A. (2014). Estereotipos y sesgos sexistas asociados al modelo de mujer enfermera en la comunicación publicitaria [Sexist stereotypes and biases associated with prototive female nurse in advertising communication]. Texto \& Contexto Enfermagem, 23(3), 530-7. doi: 1590/010407072014004120012

Castillo-Mayén M. R., \& Montes-Berges, B. (2007). Escala de estereotipos de género actuales [Current gender stereotype scale]. Iniciación a la Investigación, 2, a5. Available at http://revistaselectronicas.ujaen.es/index.php/ininv /article/view/198/179 
Celma, M., \& Acuña, A. (2009). Influencia de la feminización de la enfermería en su desarrollo profesional [Influence of the feminization of nursing in its professional development]. Revista de Antropología Experimental, 9(9), 119-136.

Cohen, F., \& Lazarus, R. S. (1979). Coping with the stresses of illness. In G. C. Stone, F. C. Cohen, \& N. E. Adler (Eds.), Health Psychology: a Handbook (pp. 217-254). Jossey-Bass, San Francisco.

Cuddy, A., Glick, P., \& Beninger, A. (2011). The dynamics of warmth and competence judgments, and their outcomes in organizations. Research in Organizational Behavior, 31, 73-98. doi: 10.1016/j.riob.2011.10.004

Dante, A., Rizzi, L., Ianderca, B., \& Palese, A. (2013). Why do university students not choose a nursing degree at matriculation? An Italian crosssectional study. International Nursing Review, $60(1)$, 129-35. doi: $10.1111 / \mathrm{j} .1466-$ 7657.2012.01037.x

Dasgupta, N., \& Asgari, S. (2004). Seeing is believing: Exposure to counterstereotypic women leaders and its effect on the malleability of automatic gender stereotyping. Journal of Experimental Social Psychology, 40(5), 642-658.

Eagly, A. H. (1987). Sex differences in social behavior: A social-role. Hillsdale, NJ: Erlbaum.

Errasti-Ibarrondo, B., Arantzamendi-Solabarrieta, M., \& Canga-Armayor, N. (2012). La imagen social de la enfermería: una profesión a conocer [Social image of Nursing: a profesión to know]. Anales del Sistema Sanitario de Navarra, 35(2), 269283. doi: 10.4321/S1137-66272012000200009

Fiske, S. (2015). Intergroup biases: a focus on stereotype content. Current Opinion in Behavioral Sciences, 3, 45-50. doi: 10.1016/j.cobeha.2015.01.010

Ho, A. K., Sidanius, J., Pratto, F., Levin, S., Thomsen, L., Kteily, N., \& Sheehy-Skeffington, J. (2012). Social dominance orientation revisiting the structure and function of a variable predicting social and political attitudes. Social Psychological Bulletin, 38(5), 583-606. doi: $10.1177 / 0146167211432765$

Hogg, M. A., Hains, S. C., \& Mason, I. (1998). Identification and leadership in small groups: Salience, frame of reference, and leader stereotypicality effects on leader evaluations. Journal of Personality and Social Psychology, 75, 1248-1263.

Lenton, A. P., Bruder, M., \& Sedikides, C. (2009). A meta-analysis on the malleability of automatic gender stereotypes. Psychology of Women Quarterly, 33(2), 183-196.

López-Zafra, E., García-Retamero, R., Diekman, A., \& Eagly, A. H. (2008). Dinámica de estereotipos de género y poder: un estudio transcultural [Dynamics of gender stereotypes and power: A crosscultural study]. Revista de Psicología Social, 23(2), 213-219. doi.org/10.1174/021347408784135788

Montes-Berges, B. \& Moya, M. C. (2009). Attitude Similarity and Stereotypicality in Leader Evaluation. The Spanish Journal of Psychology, 12(1), 258-266.

Montes-Berges, B., \& Silván-Ferrero, M. P. (2003). ¿Puede explicar la Teoría de la Dominancia Social la discriminación de género en España? [Can Social Dominance Theory explain gender discrimination in Spain?]. Encuentros en Psicología Social, 1(1), 176-179.

Mosqueda-Díaz, A., Paravic-Klijn, T., \& ValenzuelaSuazo, S. (2013). División sexual del trabajo y Enfermería [Gender division of labor and nursing]. Index de Enfermería, 22(1/2), 70-74. doi.org/10.4321/S1132-12962013000100015

Olmeadow, J., \& Fiske, S. (2007). System-Justifying ideologies moderate status=competence stereotypes: Roles for belief in a just world and social dominance orientation. European Journal of Social Psychology, 37, 1135-1148. doi: 10.1002/ejsp.428

Pratkanis, A., Breckler, S. J., \& Greenwald, A. G. (2014) (Ed.). Attitudes structure and function. New York (NY): Psychology Press.

Pratto, F., Sidanius, J., Stallworth, L. M., \& Malle, B. F. (1994). Social Dominance Orientation: A personality variable predicting social and political attitudes. Journal of Personality and Social Psychology, 67(4), 741-763. doi: 10.1037/00223514.67 .4 .741

Rodríguez-Ramírez, R., \& Escalona-Aguilar, J. R. (2007). Percepción de la imagen social de la En- 
fermería [Perception of social image on Nursing].

Educare21. Available at

http://www.enfermeria21.com/publicaciones/edu care/?option $=$ com_publicaciones\&Itemid $=66 \&$ id Articu-

$1 \mathrm{o}=38032 \&$ task $=$ verResumen $\&$ anyo $=2007 \&$ num

Publica $=4 \&$ numRevista $=38 \&$ volRevista $=$

Rudman, L. A., Moss-Racusin, C. A., Phelan, J. E., \& Nauts, S. (2012). Status incongruity and backlash effects: Defending the gender hierarchy motivates prejudice toward female leaders. Journal of Experimental Social Psychology, 48, 165-179. doi:10.1016/j.jesp.2011.10.008

Smith, E. R., \& Zárate, M. A. (1992). Exemplar-based model of social judgment. Psychological Review, 99, 3-21. doi: 10.1037/0033-295X.99.1.3

Stanley, M. H. (2012). Men in Nursing: Internalized sex-role stereotypes and their relationship to role strain and self-esteem. Phoenix (USA): UMI Dissertation Publishing.

Tajfel, H., \& Turner, J. C. (1986). The social identity theory of intergroup behavior. In Worchel, S., Austin, L.W. (Eds.), Psychology of Intergroup Relations, (pp. 7-24). Chigago: Nelson-Hall.

Tausch, N., \& Hewstone, M. (2010). Social dominance orientation attenuates stereotype change in the face of disconfirming information. Social Psychology, 41(3), 169-176. doi: 10.1027/18649335/a000024 